\title{
Cytogenetic Abnormality
}

National Cancer Institute

\section{Source}

National Cancer Institute. Cytogenetic Abnormality. NCI Thesaurus. Code C2950.

An irregularity in the number or structure of chromosomes, usually in the form of a gain

(duplication), loss (deletion), exchange (translocation), or alteration in sequence

(inversion) of genetic material. 